\title{
Language Learning Tool for Refugees: Identifying the Language Learning Needs of Syrian Refugees Through Participatory Design
}

\author{
Victoria Abou-Khali1 $^{1, *(\mathbb{D}}$, Samar Helou ${ }^{1}{ }^{\mathbb{D}}$, Brendan Flanagan $^{2}{ }^{(\mathbb{D}}$, Niels Pinkwart $^{3}$ and \\ Hiroaki Ogata ${ }^{2} \mathbb{C}$ \\ 1 Department of Social Informatics, Graduate School of Informatics, Kyoto University, Kyoto 606-8501, Japan \\ 2 Academic Center for Computing and Media Studies, Kyoto University, Kyoto 606-8501, Japan \\ 3 Department of Computer Science, Humboldt-Universität zu Berlin, 10099 Berlin, Germany \\ * Correspondence: v.aboukhalil@gmail.com
}

Received: 31 May 2019; Accepted: 4 September 2019; Published: 9 September 2019

check for updates

\begin{abstract}
A large number of refugees need to learn a new language in order to transition to, or settle in, a new country. Most refugees have access to smartphones with which they can access mobile language learning tools. However, refugees in different stages of their journeys have different language learning needs. Identifying the unique needs of refugees is essential to design language learning tools that support their language learning activities. Through a two-part participatory design study, we identify and compare the tacit and latent language learning needs of two different groups of Syrian refugees: a group in transition in Lebanon, and a group settling in Germany. The Syrian refugees we worked with in Lebanon are studying English to transition to another country with better living conditions. On the other hand, the Syrian refugees we worked with in Germany are trying to learn German to better integrate into German society. Our results show overlapping needs and specific needs for the two groups of refugees. We present our findings and discuss the opportunities and challenges for designing language learning tools to support the language learning activities of refugees.
\end{abstract}

Keywords: participatory design; refugees; language learning; mobile technologies; tacit and latent needs

\section{Introduction}

There are more than 25 million refugees worldwide. Different refugees are in different stages of migration that involve different life situations and different needs (Drachman 1992). Whether they are in a transition country waiting to relocate or settled in their final destination, language learning is often an essential part of their journey. Throughout their unstable journey, most of the refugees have access to smartphones (Gillespie et al. 2018). In this scheme, smartphones present them with opportunities for mobile language learning. It had been noted that language education for refugees should account for their unique life conditions and the circumstances that drive them to learn a new language (Kleinmann 1984). However, most of the existing and easily accessible mobile language learning tools were not built with refugees in mind, despite the size and the specific needs of the refugee population.

Previous work has been conducted to support the language learning activities of refugees. It is mainly aimed at supporting their learning of the local language of the host country to facilitate their social inclusion process, e.g., learning German in Germany (AbuJarour and Krasnova 2018; Ngan et al. 2016). These studies provide valuable insights regarding the language learning of refugees who are settled in their final destination. However, the particular language learning needs of refugees and the differences 
between the needs of settled and transitioning refugees remain unknown. Identifying the unique needs of refugees in different stages of immigration is essential to develop better language learning tools for refugees.

In this study, we aim to understand the needs of Syrian refugees in Lebanon and Germany in order to develop language learning tools. Syrian refugees in Lebanon and Germany are in different life situations and stages of their journey. Syrian refugees in Lebanon are mostly in transition. Moreover, they speak Arabic, Lebanon's official language. However, young Syrian refugees in Lebanon are trying to study English (Casalone and Puig 2015; Riller 2009) to facilitate their immigration to a safer country with better education opportunities and higher respect for human rights (UNHCR 2017b). Syrian refugees in Lebanon are facing harsh living conditions and are studying a language that is not locally spoken (UNHCR 2017b). On the other hand, Syrian refugees in Germany are learning German to better integrate and settle in their new host country. The German government provides them with free German classes, and they benefit from being continuously surrounded by the German language.

To inform the design of language learning tools for Syrian refugees, this work aims to understand and compare the tacit and latent needs of Syrian refugees transitioning in Lebanon and Syrian refugees settling in Germany. The research question that this work aims to answer is: What are the needs of Syrian refugees in Lebanon and Germany for learning languages using mobile language tools? To identify these needs, we use Participatory Design (PD) techniques. By involving the end users of a technology in its design (Muller 2003), PD can help elicit the tacit and latent needs of future users (Iversen et al. 2010 2012; Van Mechelen et al. 2017). We present the findings of a two-part participatory design study with eight Syrian refugees interested in learning English in Lebanon and ten Syrian refugees learning German in Germany. We compare their different needs and discuss the opportunities created by and challenges of meeting their language learning needs using mobile tools. The results of this study could lead to an informed design of a language learning tool for Syrian refugees to use throughout the different stages of their journey.

\section{Related Work}

\subsection{Refugees and Language Learning}

There are currently more than 25 million refugees around the world (UNHCR 2017a). Refugees typically go through three different stages of migration: (i) the premigration and departure stage, (ii) the transit stage that can include a long wait in a different country before the final relocation, and (iii) the resettlement stage during which refugees take residence in their final host country (Drachman 1992).

Among the various difficulties that refugees encounter during their journey, language presents a primary challenge (Brooker et al. 2017). Refugees use different language learning methods depending on their location and the resources available to them. These methods usually include attending language classes and using dictionaries. Furthermore, a large number of refugees use smartphones with which they have access to mobile language learning tools (Andrade and Doolin 2016; Gillespie et al. 2018). In this scheme, the development of mobile technologies for language learning can help refugees to learn a new language. Indeed, the EU highlighted the importance of such tools and supported their development through the EU Integration Action Plan of Third-Country Nationals.

Although there are common characteristics among different refugees' experiences, the effects of forced emigration vary greatly from one refugee group to another (Hatoss and Huijser 2010). Therefore, when developing language education tools for refugees, it is important to take into account their unique living conditions and the particular circumstances that drive them to learn a new language (Kleinmann 1984). Thus, different refugee groups require different considerations when designing language learning tools. Knowing the tacit and latent language learning needs of refugees can inform the design of features in a language learning tool that targets them. To our knowledge, there are no previous studies that explore the language learning needs of refugees, and no previous learning language tool has been created to support refugees in different stages of their journey. 


\subsubsection{Transition Phase: Syrian Refugees in Lebanon}

Lebanon is the country with the highest number of refugees per capita; it has 5.5 million residents and hosts more than 1.5 million refugees. The majority of the refugees in Lebanon emigrated from Syria after the eruption of the Syrian Civil War in 2011.

Syrian refugees speak Arabic, the national language of Lebanon, and therefore don't need to learn a new language for social inclusion purposes. However, some young Syrian refugees are trying to study English, (Casalone and Puig 2015; Riller 2009), which could help them immigrate to a third, safer country with better education opportunities and more respect for human rights (UNHCR 2017b). Moreover, English literacy increases their chances of enrolling and succeeding in Lebanese schools where science and math classes are taught in English or French (Orr and Annous 2018). Young Syrian refugees who are studying English while in Lebanon are in a similar situation as other refugees in transition to a third country. They cannot benefit from the advantages of being surrounded by the language they aim to learn. Moreover, being in transition often involves living in harsh and unstable conditions that are not ideal for language learning.

Most of the refugees in Lebanon cannot attend English classes due to their special socio-economic circumstances, low government support, and a lack of educational infrastructure. However, approximately $86 \%$ of Syrian refugees in Lebanon own a smartphone and have access to the internet (Talhouk et al. 2016). Hence, internet-enabled smartphones can provide refugees with the opportunity to learn languages through available online content and mobile applications (Bárcena et al. 2015).

It is important to note that existing language learning tools for refugees mainly support refugees who plan to reside in their host country long-term and aim to learn the local language for social inclusion purposes (AbuJarour and Krasnova 2018; Ngan et al. 2016). Different considerations and tools are needed to support Syrian refugees in Lebanon, and refugees in similar life situations.

\subsubsection{Settlement Phase: Syrian Refugees in Germany}

Germany has hosted approximately 720,000 Syrian refugees as of 2017 (Bundesamt für Migration und Flüchtlinge 2017). Refugees in Germany are required to attend compulsory integration and language classes. Moreover, applicants must prove proficiency in German when applying for permanent residency. Additionally, refugees must obtain a German language certification if they wish to work or attend university.

Syrian refugees studying German in Germany are in a similar situation as other refugees who are settling in a new country. They are learning the national language of their host country and struggling to build a new life in a new society (Drachman 1992).

Previous studies have explored the role of technologies in refugees' language learning and integration processes (AbuJarour and Krasnova 2018). The gaps in current language learning tools were investigated by analyzing how migrants appropriate existent language learning tools while in their settlement phase. Migrants' experiences indicated a need for additional social, meta-cognitive, and emotional support (Epp 2017). Moreover, language learning applications have been created specifically to help refugees learn a new language. Moin, for example, is a language learning application targeting refugees in Germany. It both enables and motivates local and migrant teenagers to meet for social events to practice German (Ngan et al. 2016). Ankommen, created by the German government, is another application that supports refugees with their arrival to Germany by connecting them with German-speaking volunteers. Refugee Phrasebook Interactive 2 is an application that provides refugees with one thousand basic sentences that they can use in their everyday life. However, the existing studies and applications do not elucidate the language learning needs of refugees in Germany, or refugees in similar situations. 


\subsection{Understanding the Users' Needs through Participatory Design}

Sanders (Sanders 2003) suggests accessing people's experiences by (i) listening to what they say and deducing explicit knowledge, (ii) watching what they do and deducing tacit needs, and (iii) seeing what they dream about and deducing latent needs.

Explicit knowledge is the knowledge that designers can extract from conventional study techniques such as interviews and observations.

Tacit needs are needs that people act upon but cannot express in words. Tacit needs can be deducted from observations and generative sessions (Polanyi 2009). Generative sessions are usually conducted in the early stages of the design process to identify the consumers' yet unknown needs. One way to identify those needs is by engaging the users in the design process and looking at the resulting user-generated artifacts (Sanders 2003).

Latent needs are needs that people are not yet aware of and that become realized in the future. Latent needs can also be deducted using generative sessions (Visser et al. 2005). Another common way of identifying latent needs is through the identification of recurrent themes in the participants' verbal explanations (Sanders and Colin 2002).

Researchers have also used Participatory Design (PD) techniques to extract the tacit and latent needs of users (Iversen et al. 2010, 2012; Van Mechelen et al. 2017). PD is a set of practices and theories that aim to involve the end users of a technology in its design (Muller 2003). Rather than extract knowledge from participants, the objective of PD is to co-construct knowledge (Van Mechelen et al. 2017). Through PD, designers are able to access the user's past, current, and potential experiences and provide a better design of the user's future experiences.

Spinuzzi (Spinuzzi 2005) describes a detailed methodology to conduct PD workshops. The methodology consists of three consecutive stages:

\subsubsection{Stage 1: Initial Exploration of The Work}

In this stage, the designers meet the participants and familiarize themselves with the way they work together. This stage also includes the exploration of technologies used by the participants and draws from ethnographic methods such as observations and interviews (Spinuzzi 2005).

\subsubsection{Stage 2: Discovery Process}

In the discovery process, various design thinking techniques are used to clarify the participants' needs and values. For example, future workshops could be organized where participants criticize the present, envision the future, and implement a solution (Muller 2003; Spinuzzi 2005). This stage usually involves heavy interaction between the designers and the participants and is important to understand the tacit and latent needs of the participants.

\subsubsection{Stage 3: Prototyping}

In this stage, participants and designers shape the technological artifact using a variety of prototyping techniques.

\section{Methods}

The aim of this work was to identify the tacit and latent language learning needs of Syrian refugees in Lebanon and Germany. We identified these needs through two PD workshops conducted in Lebanon and Germany over a period of two months. Each PD workshop included an introductory session and two PD sessions. Two of the authors of this paper were involved in the facilitation of the PD sessions. We chose to conduct PD workshops for four main reasons. First, the experience of refugees is difficult to access as outsiders and their participation and insight is essential to understanding their needs. PD allows access to people's experiences (Sanders 2003). Second, there is no previous knowledge of the language learning needs of refugees in different stages of their journey, and PD provides a means 
to extract those needs. Third, we assumed that the participants might have needs they are unaware of, and through the ideation phase, PD reveals some of those needs (Visser et al. 2005). Finally, we believe that the refugees should be active participants in the design process of tools that target them.

\subsection{Recruitment and Settings}

\subsubsection{Lebanon}

We recruited Syrian refugees residing in the Chouf region of Lebanon. To help us with the recruitment process, we contacted their community leader, who supervises and manages informal tented settlements in Lebanon. The community leader usually acts as the settlement supervisor and decision maker. The participants were required to (i) have internet-enabled smartphones and (ii) be learning English at the time of the study. Although we also asked the community leader for an equal representation of genders, he was able to recruit five men and only three women between the ages of 14 and 25. He explained that most of the women he contacted already had children and housekeeping duties, and had no interest in learning a new language. Moreover, the three recruited women did not own a smartphone but had limited access to the smartphones of their brother, father, or husband.

We met with the participants after $5 \mathrm{pm}$ as most of them had work during the day. The meetings and the PD workshops took place in outdoor settings in a village in the Chouf region of Lebanon. The workshop settings are shown in Figure 1.

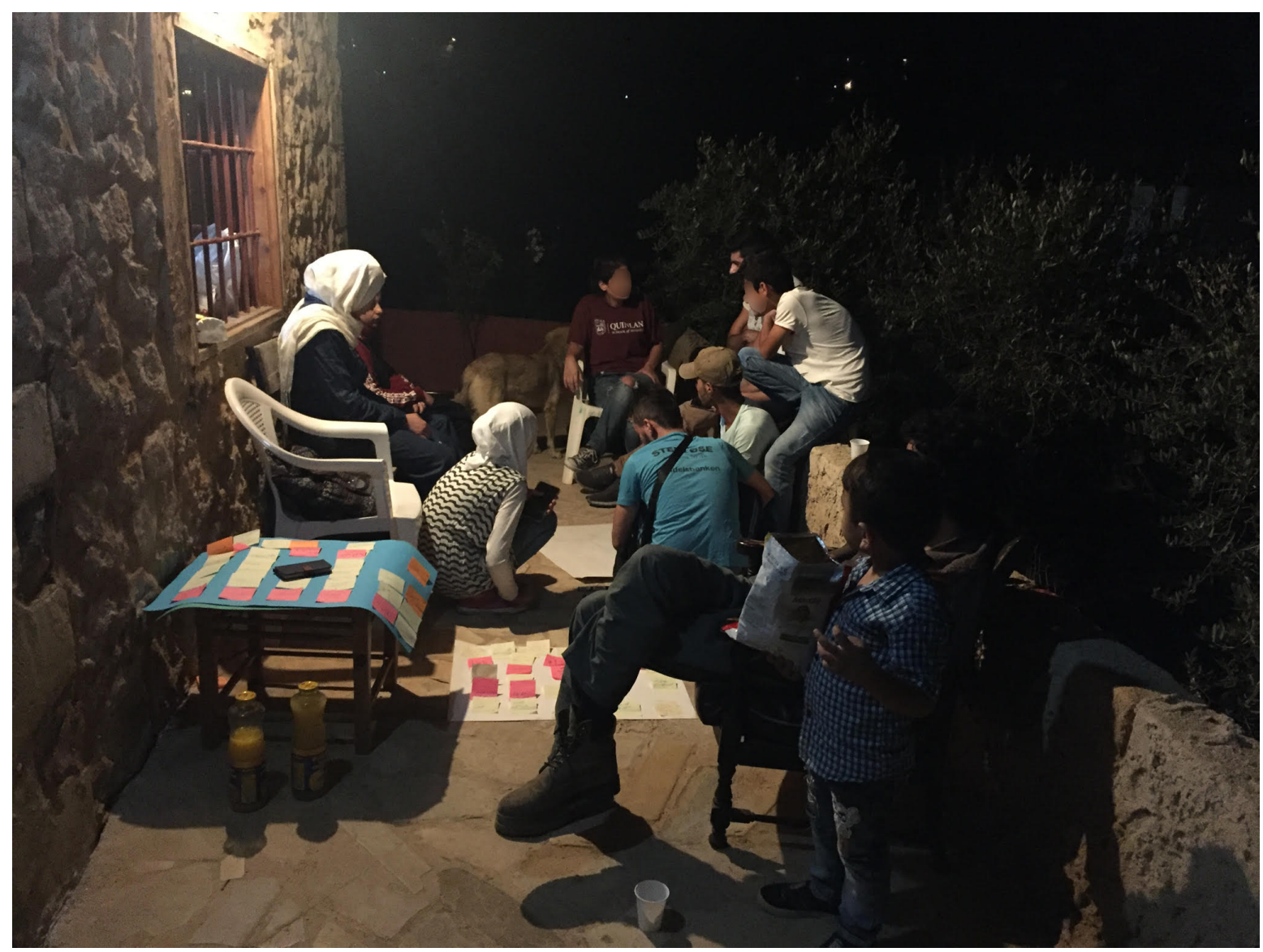

Figure 1. Settings of the participatory design workshop with the Syrian refugees in Lebanon.

\subsubsection{Germany}

Ten Syrian refugees were recruited through the ReDI School of Digital Integration, a non-profit organization based in Berlin that offers refugees technology-related training. The participants were between 26 and 54 years old. All the participants owned internet-enabled smartphones and were 
learning German at the time of the study. Although we tried to recruit an equal number of women and men, we were able to recruit seven men and only three women. Our contact explained that most of the female refugees didn't have time to join the workshops as they had to take care of their children and do housework. We used ReDI school facilities to hold the interviews and the PD workshops.

Due to the smaller number of women in the group and the possible risk of the women being less vocal in a majority male group, we separated the men and women into two different groups and conducted the workshops separately. By doing so, we aimed to provide the women with more space to express their unique personal thoughts and experiences.

We met the participants in the late afternoon as most of them were attending German classes during the day. The workshop settings are shown in Figure 2.

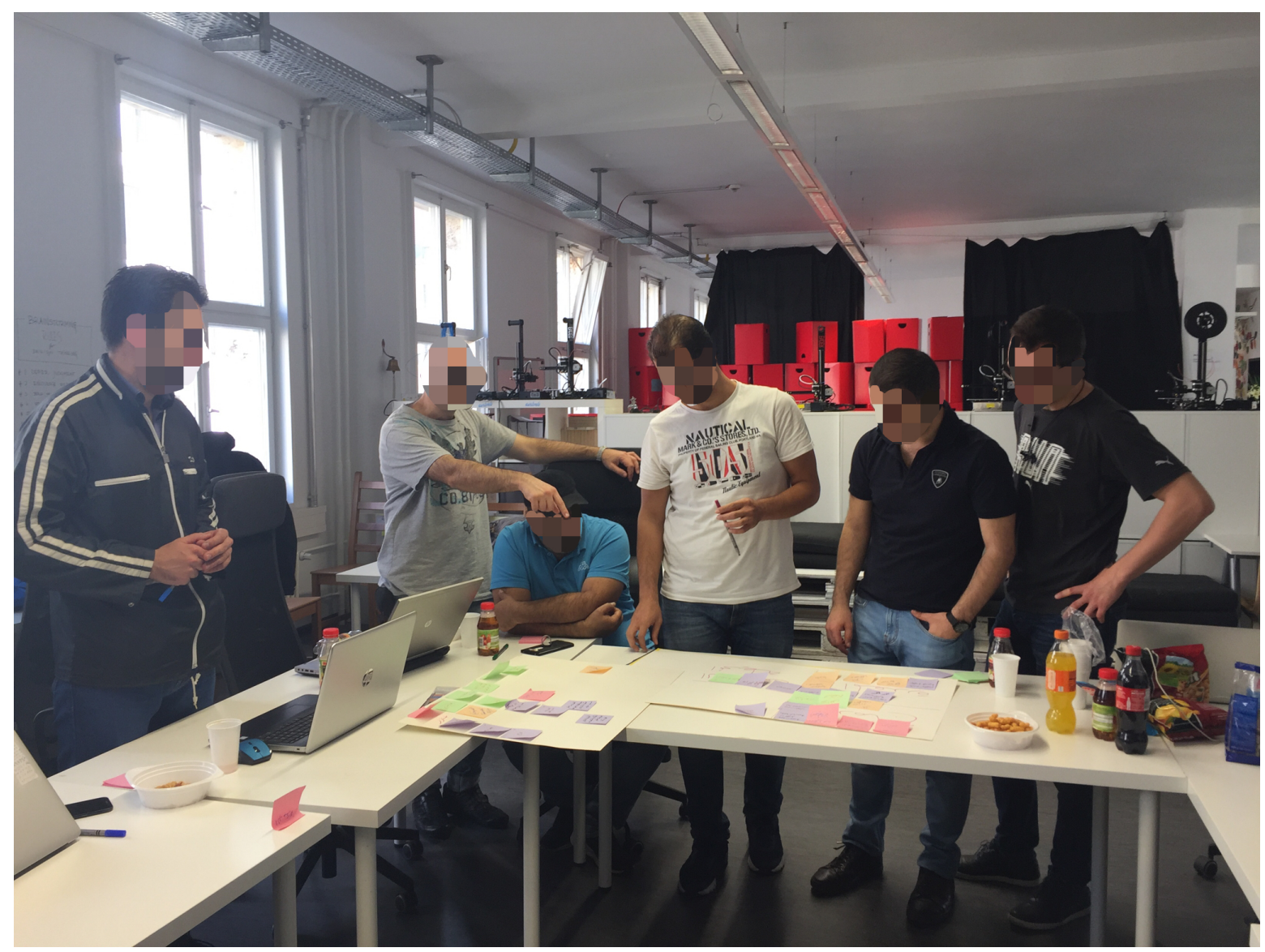

Figure 2. Settings of the participatory design workshop with the Syrian refugees in Germany.

\subsubsection{Ethical Considerations}

Prior to the start of both workshops, we explained the aim of the study to the participants and informed them that the results might be published. All the participants gave their consent to participate in the study. A parent of each minor participant gave consent for their child to participate in the workshop. The participants were informed that their names and usernames would be altered to preserve their anonymity. Moreover, we informed the participants that they could withdraw from the study at any point.

\subsubsection{Participatory Design Workshop}

We conducted the PD sessions following the methodology described by Spinuzzi (Spinuzzi 2005). 
Stage 1: Initial Exploration of the Work

First, we met the eight participants and introduced the design challenge as: "What tools would improve your language learning?" Then, we conducted individual interviews with the participants to collect the following information: their age, occupation, mode of accessing the internet, motivations for learning English, and the methods they use to learn English. The interviews were conducted in Arabic. All the interviews were recorded, translated from Arabic to English, and transcribed.

Finally, we introduced a free language learning website to the participants and asked them to use it for a period of ten days. The goals of this assignment were to understand the extent of their familiarity with technologies and give them the opportunity to reflect in preparation for the future PD sessions.

\section{Stage 2: Discovery Process}

The session took the form of a future workshop. Future workshops are a commonly used workshop format used in PD. Future workshops proceed in three consecutive stages: (i) criticizing the present, (ii) envisioning the future, and (iii) implementing (Muller 2003).

Our session was conducted as follows:

Criticizing the present. In this stage, we started by introducing the participants to the concept of brainstorming. Then, we asked them to brainstorm on the difficulties they encounter while learning English or German. We asked the participants to write down each difficulty on a separate sticky note. After the brainstorming session, the participants shared their input with each other to gain a shared understanding of the problems they face. Finally, the participants grouped the similar difficulties together and chose three difficulties they would like to focus on.

Envisioning the future (Sanders 2003). In this stage, we asked the participants to imagine the lexicon they would like to learn in the target language and how they would like to learn it, if all possibilities were open to them. The session was organized as follows: First, we conducted a second brainstorming session where the participants wrote down the different lexicon they would like to learn (e.g.,: lexicon to find a job, lexicon to buy food in the supermarket). Each type of lexicon was written down on a separate sticky note. Following the brainstorming session, the participants shared their input with the other group members to gain a shared understanding of their aspirations. The participants were also asked to group similar lexicons together. Next, we asked the participants to brainstorm ideas for language learning tools that would help them learn English. We asked participants to come up with as many ideas as possible without worrying about the originality or feasibility of their ideas. The participants grouped the ideas into different categories and mapped them to the different difficulties and lexicons produced previously. Finally, the participants chose three ideas and combined them into one idea that they would later prototype.

\section{Stage 3: Prototyping}

In this stage, we asked the participants to paper prototype their final idea using cardboard, pens, and colored markers.

\subsubsection{Identifying the Tacit and Latent Needs}

The tacit and latent needs of the refugees were identified using a thematic analysis approach. One of the authors conducted the analysis. The results of the analysis were reviewed and confirmed by another author. First, we transcribed the content of the PD sessions. The transcribed data was composed of: (i) the sticky notes the participants produced during the brainstorming session, (ii) the explanations that they gave when presenting their ideas, and (iii) the explanations that they gave when presenting the final prototype. 
The thematic analysis was conducted separately for the two sessions criticizing the present and envisioning the future. The results obtained from the thematic analysis of the session criticizing the present correspond to the refugees' tacit needs. The results obtained from the thematic analysis of the session envisioning the future correspond to the refugees' latent needs.

For each session, we conducted the thematic analysis following the six-phase guide of Braun and Clarke (2006):

1. Familiarization with the data. As we collected the data through interactive means, we had a prior knowledge of the data along with some initial thoughts on it. Despite this, we went through the data again for a deeper familiarization with it.

2. Coding the data. While reading the collected information, we generated a list of codes and associated them with small chunks of the appropriate data.

3. Searching for themes. We refocused the analysis on broader level themes by combining several codes together.

4. Reviewing themes. In this phase, we refined the chosen themes by eliminating some that had too little data associated with them and merging others to form new themes.

5. Defining and naming the themes. At this stage, we identified the essence of the themes and translated it in terms of needs.

6. Producing the report. The resulting needs were described (see result section).

\section{Results}

We report our findings in three sections. The explicit knowledge section describes the participants' motivations to learn a new language, the methods they use to learn the new language, and their familiarity with mobile technologies. The tacit needs section presents the unarticulated needs of Syrian refugees regarding language learning. Finally, the latent needs section presents the needs regarding language learning that Syrian refugees have and are not yet aware of. For each of the sections, we report the results that are common to the refugees in Lebanon and Germany and the results that are specific to each of the two groups.

\subsection{Explicit Knowledge}

Explicit knowledge was extracted from the individual interviews with the participants and our observations of their familiarity with mobile technologies.

\subsubsection{Motivations to Learn the Target Language}

\section{Syrian Refugees in Lebanon}

In the interviews, the participants reported three main reasons for learning English, which appear to be directly linked to their occupations. In fact, the participants who were enrolled in Lebanese schools wanted to learn English to understand the science and math classes and succeed at school. One female participant, a mother whose children attend Lebanese schools, wanted to learn English to help her children succeed at school. Even though it is essential for Syrian refugees to learn English for educational purposes, they reported that their end goal is to leave Lebanon. The participants who were single and employed reported that they want to learn English to facilitate their exit from Lebanon. Two young male refugees reported that they will not return to Syria because they escaped the compulsory military service there, but they cannot foresee a future for themselves in Lebanon. Another male refugee wanted to leave Lebanon for Canada, where his wife resides. As she was underage when they got married, she did not report her marriage upon arrival to Canada, and therefore cannot help him get a spouse visa. Her husband is now trying to immigrate there; he explained, "Learning English will give me more points and facilitate the approval of my application". 


\section{Syrian Refugees in Germany}

During the interview phase, participants expressed their desire to learn German to be able to settle in Germany. Six participants reported that learning German will allow them to enroll at university or find full-time employment. One noted, "We need a certificate of language to enroll at university or to find any kind of job". Three participants who are currently enrolled in a German university reported that learning German is essential to stay in Germany, be part of the society, and "maybe try to become a German citizen". One female participant stated that she came to Germany to be close to her children who were already there. Learning German will allow her to stay close to them; she said, "I am not in this situation by my own will, I was forced into it. The kids left Syria and I cannot live without them. I want to learn German to be able to work here and stay close to them". Learning German is a way for all the participants to build a life in Germany and the reported motivations were common to the participants regardless of gender, age and occupation.

\subsubsection{Methods of learning the target language}

\section{Syrian Refugees in Lebanon}

The methods for learning English depended on the occupation of the participants and their gender. The participants who were enrolled in Lebanese schools learn English at school. A 23-year-old male participant uses Duolinguo, a mobile application, to learn English. The rest of the participants rarely attend English sessions provided by NGOs. A female participant reported using dictionaries to learn English. As mentioned earlier, female participants did not own smartphones and used smartphones belonging to their brothers, husbands, or fathers to connect to the internet. This restricts their connectivity time and limits their possibilities of using mobile technologies for language learning.

\section{Syrian Refugees in Germany}

All participants reported learning German through the free German classes offered by the German government. The participants were attending classes ranging in level from A1 to $\mathrm{C} 1$ (A1 being the most basic level and $\mathrm{C} 1$ the second most advanced level). Moreover, male participants reported using language learning applications to improve their language skills, whereas female participants were learning mainly through the language classes. The Language applications used by men included Google translate, Flashcards, Rosetta Stone and Arabdict, a crowdsourcing Arabic-German dictionary.

\subsubsection{Familiarity with Mobile Technologies}

\section{Syrian Refugees in Lebanon}

We asked the participants to sign up for and use a language learning website in order to understand the extent of their familiarity with technologies. The participants were required to input an email address, create an account on the website and learn a couple of words. Most of the participants had email addresses but could not remember them. The facilitators helped retrieve them by looking at other applications on their phones. Most of the participants were familiar with the Arabic keyboard. Two participants had difficulties typing in Arabic due to their low literacy level. The participants were very slow while using the English keyboard as they took time to search for each letter.

\section{Syrian Refugees in Germany}

We followed the same process in Germany, asking the participants to sign up for and use a language learning website in order to assess their familiarity with technologies. Nine of the participants were very familiar with the process and easily performed the tasks using the English and Arabic Keyboard. However, the men showed more familiarity with the English keyboard compared with the women. The oldest participant, a 54-year-old woman, took more time to complete tasks using the 
website compared to the other participants. She also had difficulties with the signing up process and the English keyboard and needed assistance from the facilitator.

A summary of the explicit knowledge collected through the interviews in the exploration phase is presented in Tables 1 and 2.

Table 1. How and why are the participants learning English in Lebanon.

\begin{tabular}{|c|c|c|c|c|c|c|c|}
\hline Participant & Gender & Age & Occupation & $\begin{array}{r}\text { Learning } \\
\text { Method }\end{array}$ & Motivation & $\begin{array}{c}\text { Internet } \\
\text { Access Method }\end{array}$ & $\begin{array}{l}\text { Familiarity with } \\
\text { Mobile Technology }\end{array}$ \\
\hline P1 & Female & 16 & $\mathrm{~N} / \mathrm{A}$ & English sessions & Study in Canada & Father's phone & Unfamilar \\
\hline $\mathrm{P} 2$ & Female & 14 & Student & At school & Succeed at school & Father's phone & Unfamilar \\
\hline P3 & Male & 15 & Student & At school & Succeed at school & Own phone & Familar \\
\hline $\mathrm{P} 4$ & Male & 23 & Plumber & Duolingo & Move to Canada & Own phone & Familar \\
\hline P5 & Male & 15 & Mechanic & English sessions & Leave Lebanon & Own phone & Familar \\
\hline P6 & Male & 18 & Mechanic & English sessions & Leave Lebanon & Own phone & Familar \\
\hline P7 & Female & 25 & $\mathrm{~N} / \mathrm{A}$ & Dictionnary & Help her children & Husband's phone & Unfamilar \\
\hline P8 & Male & 18 & Student & At school & Succeed at school & Own phone & Unfamilar \\
\hline
\end{tabular}

Table 2. How and why are the participants learning German in Germany.

\begin{tabular}{|c|c|c|c|c|c|c|c|}
\hline Participant & Gender & Age & Occupation & $\begin{array}{r}\text { Learning } \\
\text { Method }\end{array}$ & Motivation & $\begin{array}{c}\text { Internet } \\
\text { Access Method }\end{array}$ & $\begin{array}{l}\text { Familiarity with } \\
\text { Mobile Technology }\end{array}$ \\
\hline P1 & Female & 54 & $\mathrm{~N} / \mathrm{A}$ & German school & Find employment & Own phone & Unfamiliar \\
\hline $\mathrm{P} 2$ & Female & 29 & $\mathrm{~N} / \mathrm{A}$ & German school & Enroll at university & Own phone & Familiar \\
\hline P3 & Female & 26 & $\mathrm{~N} / \mathrm{A}$ & German school & Enroll at university & Own phone & Familiar \\
\hline $\mathrm{P} 4$ & Male & 26 & Student & Applications & Stay in Germany & Own phone & Familiar \\
\hline P5 & Male & 31 & Student & Applications & Stay in Germany & Own phone & Familiar \\
\hline P6 & Male & 30 & Student & Applications & Get naturalized & Own phone & Familiar \\
\hline P7 & Male & 39 & $\mathrm{~N} / \mathrm{A}$ & German school & Find employment & Own phone & Familiar \\
\hline P8 & Male & 35 & $\mathrm{~N} / \mathrm{A}$ & German school & Find employment & Own phone & Familiar \\
\hline P9 & Male & 29 & $\mathrm{~N} / \mathrm{A}$ & German school & Find employment & Own phone & Familiar \\
\hline P10 & Male & 39 & $\mathrm{~N} / \mathrm{A}$ & German school & Find employment & Own phone & Familiar \\
\hline
\end{tabular}

\subsection{Tacit Needs}

We present below the tacit needs that we identified through the thematic analysis.

\subsubsection{Common Needs of Syrian Refugees in Lebanon and Germany}

Need for Time Management

During the brainstorming session, the participants in Lebanon reported lacking time to study English. The participants who were employed work all week and do not benefit from any days off. Some of the students go to school for half a day and work for the other half. Moreover, participants reported being tired in the evenings when they finally had the opportunity to study English.

The participants in Germany reported a lack of time to review the German lessons learned during the day. Due to their unstable housing situation, appointments with government officials, and long amounts of time spent on Berlin's public transport system, participants have little time left to study German. Moreover, female participants reported that their housekeeping and child-rearing duties were time consuming: "I wish the German government provided housekeeping training courses for Syrian men".

\section{Need for Recollection}

While brainstorming the difficulties of learning English, the participants expressed their tacit need for recollection. Participants in Lebanon reported their inability to remember the vocabulary they learn. In the discussion that followed, the participants expressed their discouragement, e.g., "I forget a lot. I learn a word, then I forget it".

The participants in Germany reported that they often forget uncommon words that they learn as they don't have the opportunity to use or hear them. 
Need for Social Learning

The participants in Lebanon reported feeling lonely when learning English. Few people around them are interested in learning a new language or are supportive of their endeavor.

The participants in Germany expressed the need for social learning with Germans, in contrast to the refugees in Lebanon who wished they could learn with their compatriots. Participants in Germany reported a desire for more contact and exchange with Germans. The tacit need for social learning was expressed in the brainstorming session as well as in the following discussions.

\subsubsection{Tacit Needs of Syrian Refugees in Lebanon}

\section{Need for Discipline}

The tacit need for discipline was extensively expressed by the participants. On multiple occasions throughout the workshop, the participants complained about their lack of commitment to learning English. Moreover, three participants wished there was a teacher who was willing to teach them English because then they "will have to attend".

Need for Motivation

The participants reported that they often see themselves losing their motivation to study English. "It is hard to find a job if you are Syrian in Lebanon, and it is hard to leave Lebanon. Sometimes, I just don't feel like learning anymore".

Need for Calm

Participants reported living in very noisy environments that do not support tasks that require concentration. Moreover, they reported being continuously distracted by members of the family or members of the community as it is common for a large number of people to live in the same house.

\subsubsection{Tacit Needs of Syrian refugees in Germany}

Need for Contextual Vocabulary Teaching

The participants expressed the need for specific vocabulary knowledge. Polysemous words in the German language are problematic: "Words have different meanings, I don't know how to use them". Moreover, participants stated difficulties understanding and using bureaucratic vocabulary or field-specific terms.

\section{Need for Identity Appreciation}

Participants extensively expressed the tacit need for the appreciation of their identity: "We have an old culture and civilization, this is what I would like to share". "People ask me if you we have cars in Syria, of course we have cars in Syria. I don't have the vocabulary to explain what Syria is".

\subsection{Latent Needs}

We present below the latent needs identified from the thematic analysis.

\subsubsection{Common Latent Needs of Syrian Refugees in Lebanon and Germany}

Need for Self-Expression

When envisioning the future, the participants reported a latent need for self-expression. All participants in Lebanon expressed their desire to learn how to introduce themselves and communicate with people. Moreover, their ideal language learning tool would allow them to go 
to the market and "sell" things. Participants wished they could be able to present themselves well in work or visa interviews. A participant shared his desire to learn "big words" to express himself better.

In Germany, participants wished they had the skills to speak about philosophy or social issues with Germans: "I am not able to express my deep thoughts or to conduct interesting discussions".

Need for Fun

When describing ideal language learning tools, the participants in Lebanon and Germany expressed the desire for "a fun application" or "an entertaining tool".

The participants in Germany imagined an application that would allow them to watch movies based on their vocabulary knowledge: "The content we find is usually either boring or very difficult to understand".

\subsubsection{Latent needs of Syrian Refugees in Lebanon}

\section{Need for Foreigners}

During the ideation session, participants expressed a latent need to meet and interact with non-Arab foreigners. Refugees in Lebanon often come directly from Syria and have few opportunities to meet non-Arab foreigners. Many application ideas involved a "foreign teacher", "seeing foreigners", "talking with foreigners", and "traveling and meeting foreigners". Interaction with foreigners was a recurrent topic in the participants' discourse.

Need for the Presence of English

Through the ideation session, participants showed a latent need for the presence of English. When imagining the future, participants imagined a world where they will be surrounded by English: "I would like to see ads in English on billboards, with an Arabic translation", "I would like to have all the names of things in the supermarket in English".

\subsubsection{Latent Needs of Syrian Refugees in Germany}

\section{Need for German Friends}

Participants repeatedly expressed their need for a close relationship with a German person. During the ideation session, participants imagined a solution that would allow them to have German friends. The female participants who were wearing veils expressed this need more strongly. They reported feeling a reluctance from Germans to have social interactions with them: "I think it is much easier for men and non-hijabi women to learn German and interact with Germans" .

Need for Feeling Equal

The need for equality was expressed in different forms. Some participants reported that they prefer speaking English with Germans, as it puts them on equal ground: "They are not speaking their native language, I am not speaking mine, the interaction is more equal". Moreover, some participants expressed the desire to volunteer "as a way to give something to German society": "We are in an inferior position, Germans need to be patient when we speak German slowly. I would like to contribute in some way". Finally, during the ideation session, participants proposed the creation of an Arab-German channel where German movies are translated to Arabic and vice-versa: "They will learn about our culture, and will learn more about theirs".

A summary of the tacit and latent language learning needs of the refugees is presented in Table 3. 
Table 3. Tacit and latent language learning needs for Syrian refugees in Lebanon and Germany.

\begin{tabular}{ll}
\hline Category & Need \\
\hline Common tacit needs & Need for time management \\
& Need for recollection \\
& Need for social learning \\
\hline Tacit needs of Syrian refugees in Lebanon & Need for discipline \\
& Need for motivation \\
& Need for calm \\
\hline Tacit needs of Syrian refugees in Germany & Need for contextual vocabulary learning \\
& Need for identity appreciation \\
\hline Common latent needs & Need for self-expression \\
\hline Latent needs of Syrian refugees in Lebanon & Need for fun \\
\hline Latent needs of Syrian refugees in Germany & Need for the presence of English \\
\hline & Need for ferman friends \\
\hline
\end{tabular}

\section{Discussion}

We conducted PD workshops with Syrian refugees in Lebanon and Germany and identified their tacit and latent language learning needs. In addition, we presented the Syrian refugees' motivations to learn a new language, the learning methods they use, and their familiarity with mobile technologies through interviews and observations.

It has been noted that the tacit and latent needs are derived from a rather small number of refugees. Despite the obvious limitations, the results are relevant for two main reasons. First, to our knowledge, no previous study has aimed to understand the needs of refugees throughout the different stages of their journey, even though those populations require special attention and support. Second, our study retrieved the tacit and latent needs of refugees through PD sessions. Therefore, the results deepen the understanding of (i) what refugees say, (ii) what they need and don't express in words, and (iii) what they will need in the future in the context of language technologies.

In the following sections, we discuss our findings and the opportunities for designing language learning tools that support refugees' language learning processes.

\subsection{General Language Learning Needs of Refugees}

All learners have common needs and many of them have been explored extensively. The need for fun has been explored as a way to learn more effectively (Perifanou 2009) and is not unique to refugees. Additionally, our findings show the need for social learning that could be associated with the benefits of learning within a community of practice (Lave 1991). However, some of the needs that we found are stronger in refugee communities and others are specific to them. Previous studies confirm that the need for socio-collaborative learning is strongly present in refugee communities (Epp 2017). Moreover, our results confirmed the need for language learning tools specifically targeting refugees and answering their unique needs. In fact, the tacit needs for recollection and calm are more likely to be present within refugee communities. The need for recollection was highly present in the discourse of the refugees in Lebanon and Germany and could be caused by memory impairment. Previous studies on refugees showed that PTSD, depression, and general distress could lead to memory impairment (Johnsen and Asbjørnsen 2009). Moreover, the tacit need for calm is confirmed by a previous study stating that noise in the camp is one of the most frequent problems reported by refugees (Benson-Martin et al. 2017). The refugees in Lebanon and Germany expressed the needs for time management and identity appreciation. These two needs are directly related to the difficulties of settling in a new country and being a refugee. 


\subsection{Different Language Learning Needs of Refugees in Lebanon and Germany}

Some of the tacit and latent needs identified in this work confirmed the difference of language learning needs between the Syrian refugees in Lebanon and Germany.

The latent need for foreigners is particular to the Syrian refugees in Lebanon. Syrian refugees in Lebanon often come directly from Syria and have few opportunities to meet non-Arab foreigners. Meeting or having contact with foreigners would allow them to put into practice what they have learned, thereby boosting their confidence and enabling them to communicate with the external world. The refugees in Lebanon also expressed a latent need for a greater presence of English in their environment. Refugees learning the language of their host country encounter their target language continuously throughout their daily life. However, Syrian refugees in Lebanon expressed a desire for a more concrete application of their newly learned skills and more opportunities to be exposed to the language.

On the other hand, Syrian refugees in Germany expressed the need for identity appreciation, a need that has been shown to create stress among refugees as an impact of acculturation (Bhugra and Becker 2005). The need for a German friend, or a friend from the host culture, is another need that is specific to refugees in the settlement phase.

Interestingly, some Syrian refugees in Germany reported choosing to speak English, not German, in an attempt to be on equal ground with German citizens. This purposeful avoidance of speaking German negatively affects their chances of practicing the target language.

The refugees in Lebanon expressed a need for motivation whereas the refugees in Germany did not. This could be due to the different nature of their goals. For Syrian refugees in Lebanon, learning English could help them, but is not mandatory nor does it guarantee that they will achieve their goals. Getting their visa applications approved or succeeding in Lebanese schools relies on many other factors. Conversely, learning German is mandatory for Syrian refugees to achieve their goal of long-term settlement in Germany. Moreover, the effect of learning German is concrete and palpable in their everyday interactions.

\subsection{Implications for the Design of Language Learning Tools}

The previously presented needs provide multiple opportunities for designing language learning tools to support refugees in their language learning activities. These features could be included in language learning tools for Syrian refugees in Lebanon and Germany, or refugees in similar situations.

To answer the need for time management and discipline, refugees can be provided with data that recommends the best times and locations for studying based on their past learning activities. Data on log in study times have already been collected in existing language learning tools, as well as location data in some cases. These data points could be analyzed to provide such recommendations.

To answer the need for recollection, language learning tools could measure the retention rate of the refugees by providing flashcard type quizzes. The data that is collected from the quizzes could be analyzed later to adapt a spaced repetition system based on the individual recollection needs of the refugees.

The need for motivation could be answered by analyzing the refugees' performance on the language learning tool and providing them with the opportunity to share their advancement reports with embassies or schools. By doing so, the language learning tools would provide them with a concrete and palpable outcome that they could use to achieve their goals.

The need for calm could be answered by encouraging the refugees to study when a calm environment is detected. The noises surrounding the learner could be detected through the phone's microphone.

Refugees reported the need for contextual vocabulary learning. To meet this need, dictionary and location data could be collected and analyzed to understand the lexicon that the refugees are potentially interested in learning in specific contexts. Based on this analysis, the language learning tool could provide the refugees with new words to learn, or previously learned word to recollect, in those contexts. 
Moreover, the latent need for the presence of English, expressed by Syrian refugees in Lebanon, could be answered through lifelogging ubiquitous language learning features that recommend objects to learn depending on the location of the learner. Ubiquitous language learning environments have shown to be beneficial for language learning in that they help the language become embedded in the daily life of the learner (Ogata et al. 2011). Learners should be able to upload logs offline. The synchronization of the logs and the recommendation system could be activated when an internet connection is available.

The refugees reported that the needs for identity appreciation and self-expression are affecting their learning. To answer these needs, language learning tools can collect information on the work, educational background, and interests of the refugees. Based on this information, the tool could provide them with language learning materials that allow them to talk about their Syrian identity, themselves, and their interests. Furthermore, by collecting feedback on the learning material, the tool can recommend new learning material based on what other refugees with similar backgrounds found useful.

The needs for social learning, foreigners, German friends, and a feeling of equality were extensively reported by the refugees throughout the discussions. However, those needs, social in their nature, can hardly be met through traditional language learning tools. We encourage researchers and designers to further investigate ways to address these challenges through language tools that support refugees in their learning activities.

\section{Conclusions}

Through Participatory Design workshops, this work identified the tacit and latent language learning needs of Syrian refugees in Lebanon and Germany. The Syrian refugees in Lebanon and Germany appeared to have both overlapping and distinct tacit and latent needs. The tacit needs for time management, recollection, and social learning were common to the participants in Lebanon and Germany. Participants in Lebanon expressed the tacit needs for discipline and calm whereas participants in Germany communicated the tacit needs for contextual learning and identity appreciation. Moreover, the latent needs for self-expression and fun were common to the two refugee groups. The latent needs for foreigners and the presence of English were expressed by the Syrian refugees in Lebanon whereas the Syrian refugees in Germany communicated the latent needs for German friends and a feeling of equality. Based on these results, we discussed the opportunities and challenges for designing language learning tools to support the language learning activities of refugees.

Author Contributions: Conceptualization, V.A.-K.; Methodology, V.A.-K., S.H.; Discussion on collected data, V.A.-K., S.H., N.P., and H.O.; Formal Analysis, V.A.-K.; Resources, H.O. and N.P.; Data Curation, V.A.-K.; Writing-Original Draft Preparation, V.A.-K.; Writing-Review \& Editing, V.A.-K., S.H., N.P., B.F. and H.O.; Supervision, H.O., B.F. and N.P.; Project Administration, V.A.-K., B.F. and H.O.

Funding: This research was funded by the Leading Graduate Schools Program "Collaborative Graduate Program in Design", Kyoto University, Japan and by the JSPA KANHEKI Grant Number JP12K34567.

Acknowledgments: We thank Jad Hajjar for recruiting the participants in Lebanon, assisting us with the conduction of the workshops and arranging the meeting space. We also thank Vanessa Abou-Khalil, Edouard Keyrouz and Selim Keyrouz for helping with the facilitation of the workshops. We would also like to show our gratitude to ReDI School of Digital Integration for helping us recruiting the participants in Berlin and providing us with the meeting space.

Conflicts of Interest: The authors declare no conflict of interest.

\section{References}

AbuJarour, Safa, and Hanna Krasnova. 2018. E-learning as a means of social inclusion: The case of syrian refugees in germany. Paper presented at Twenty-fourth Americas Conference on Information Systems, New Orleans, LA, USA, August 16-18.

Andrade, Antonio Diaz, and Bill Doolin. 2016. Information and communication technology and the social inclusion of refugees. Mis Quarterly 40: 405-16. [CrossRef] 
Bárcena, Elena, Timothy Read, Joshua Underwood, Hiroyuki Obari, Diana Cojocnean, Toshiko Koyama, Antonio Pareja-Lora, Cristina Calle, Lourdes Pomposo, Noa Talaván, and et al. 2015. State of the art of language learning design using mobile technology: Sample apps and some critical reflection. Paper presented at the Critical CALL-Proceedings of the 2015 EUROCALL Conference, Padova, Italy, August 26-29.

Benson-Martin, Janine, Angelika Edwards, and Brigitte Joggerst. 2017. Determining the mental health \& psycho-social needs of a refugee population in pforzheim/enzkreis: First results. Das Gesundheitswesen 79: A178.

Bhugra, Dinesh, and Matthew A Becker. 2005. Migration, cultural bereavement and cultural identity. World Psychiatry 4: 18. [PubMed]

Braun, Virginia, and Victoria Clarke. 2006. Using thematic analysis in psychology. Qualitative Research in Psychology 3: 77-101. [CrossRef]

Brooker, Abi, Jeanette Lawrence, and Agnes Dodds. 2017. Using digital concept maps to distinguish between young refugees' challenges. Journal of Interactive Media in Education 2017: 4. [CrossRef]

Bundesamt für Migration und Flüchtlinge. 2017. Das Bundesamt in Zahlen 2017: Asyl, Migration und Integration. Available online: http:/ / www.bamf.de/SharedDocs/Anlagen/DE/Publikationen/Broschueren/bundes amt-in-zahlen-2017.pdf?_blob=publicationFile (accessed on 18 October 2018).

Casalone, Manuela, and Nicolas Puig. 2015. Enfances en Migration une Étude sur les Enfants Syriens Réfugiés au Liban. Paris: Université Paris Diderot - Paris 7, pp. 23-24.

Drachman, Diane. 1992. A stage-of-migration framework for service to immigrant populations. Social Work 37: 68-72.

Epp, Carrie Demmans. 2017. Migrants and mobile technology use: Gaps in the support provided by current tools. Journal of Interactive Media in Education 2017: 2.

Gillespie, Marie, Souad Osseiran, and Margie Cheesman. 2018. Syrian refugees and the digital passage to europe: Smartphone infrastructures and affordances. Social Media+ Society 4. [CrossRef]

Hatoss, Aniko, and Henk Huijser. 2010. Gendered barriers to educational opportunities: Resettlement of sudanese refugees in australia. Gender and Education 22: 147-60. [CrossRef]

Iversen, Ole Sejer, Kim Halskov, and Tuck Wah Leong. 2010. Rekindling values in participatory design. Paper presented at the 11th Biennial Participatory Design Conference, Sydney, Australia, November 29-December 3. New York: ACM, pp. 91-100.

Iversen, Ole Sejer, Kim Halskov, and Tuck Wah Leong. 2012. Values-led participatory design. CoDesign 8: 87-103. [CrossRef]

Johnsen, Grethe, and Arve Asbjørnsen. 2009. Verbal learning and memory impairments in posttraumatic stress disorder: The role of encoding strategies. Psychiatry Research 165: 68-77. [CrossRef] [PubMed]

Kleinmann, Howard H. 1984. Understanding refugee second language learning. Japan Association of Language Teachers Journal 6: 209-19.

Lave, Jean. 1991. Situating learning in communities of practice. Perspectives on Socially Shared Cognition 2: 63-82.

Muller, Michael J. 2003. Participatory design: the third space in hci. Human-Computer Interaction: Development Process 4235: 165-85.

Ngan, Hong Yin, Anna Lifanova, Juliane Jarke, and Jan Broer. 2016. Refugees welcome: Supporting informal language learning and integration with a gamified mobile application. In European Conference on Technology Enhanced Learning. Berlin: Springer, pp. 521-24.

Ogata, Hiroaki, Mengmeng Li, Bin Hou, Noriko Uosaki, Moushir M. El-Bishouty, and Yoneo Yano. 2011. Scroll: Supporting to share and reuse ubiquitous learning log in the context of language learning. Research $\mathcal{E}$ Practice in Technology Enhanced Learning 6: 69-82.

Orr, Mike, and Samer Annous. 2018. There is no alternative! student perceptions of learning in a second language in lebanon. Journal of Language and Education 4: 79-91. [CrossRef]

Perifanou, Maria A. 2009. Language micro-gaming: Fun and informal microblogging activities for language learning. In World Summit on Knowledge Society. Berlin: Springer, pp. 1-14.

Polanyi, Michael. 2009. The Tacit Dimension. Chicago: University of Chicago Press.

Riller, Frauke. 2009. On the Resettlement Expectations of Iraqi Refugees in Lebanon, Jordan, And Syria. Geneva: UNHCR and ICMC.

Sanders, Elizabeth. 2003. From user-centered to participatory design approaches. In Design and the Social sciences. Boca Raton: CRC Press, pp. 18-25. 
Sanders, Elizabeth, and William Colin. 2002. Harnessing people's creativity: Ideation and expression through visual communication. In Focus Groups: Supporting Effective Product Development. Boca Raton: CRC Press, pp. $147-58$

Spinuzzi, Clay. 2005. The methodology of participatory design. Technical Communication 52: 163-74.

Talhouk, Reem, Sandra Mesmar, Anja Thieme, Madeline Balaam, Patrick Olivier, Chaza Akik, and Hala Ghattas. 2016. Syrian refugees and digital health in lebanon: Opportunities for improving antenatal health. Paper presented at the 2016 CHI Conference on Human Factors in Computing Systems, San Jose, CA, USA, May 7-12. New York: ACM, pp. 331-42.

UNHCR. 2017a. Unhcr Statistical Yearbook. Available online: http:/ / www.unhcr.org/figures-at-a-glance.html (accessed on 25 October 2018).

UNHCR. 2017b. Vulnerability Assessment of Syrian Refugees in Lebanon 2017. Available online: https://data2.un hcr.org/en/documents/download/61312 (accessed on 18 September 2018).

Van Mechelen, Maarten, Jan Derboven, Ann Laenen, Bert Willems, David Geerts, and Vero Vanden Abeele. 2017. The glid method: Moving from design features to underlying values in co-design. International Journal of Human-Computer Studies 97: 116-28. [CrossRef]

Visser, Froukje Sleeswijk, Pieter Jan Stappers, Remko Van der Lugt, and Elizabeth BN Sanders. 2005. Contextmapping: Experiences from practice. CoDesign 1: 119-49. [CrossRef]

(C) 2019 by the authors. Licensee MDPI, Basel, Switzerland. This article is an open access article distributed under the terms and conditions of the Creative Commons Attribution (CC BY) license (http://creativecommons.org/licenses/by/4.0/). 